\title{
Treatment of Obesity in Patients With Diabetes
}

Carolyn T. Bramante, ${ }^{1}$ Clare J. Lee, ${ }^{2}$ and Kimberly A. Gudzune ${ }^{1,3}$

${ }^{1}$ Division of General Internal Medicine, ${ }^{2}$ Division of Endocrinology, Diabetes, and Metabolism, and ${ }^{3}$ The Welch Center for Prevention, Epidemiology and Clinical Research, The John Hopkins University, Baltimore, MD

Corresponding author: Carolyn T. Bramante, cb@jhmi.edu

https://doi.org/10.2337/ds17-0030

(C)2017 by the American Diabetes Association. Readers may use this article as long as the work is properly cited, the use is educational and not for profit, and the work is not altered. See http:/l creativecommons.org/licenses/by-nc-nd/3.0 for details.

IN BRIEF More than $90 \%$ of patients with diabetes have overweight or obesity. Whereas weight gain and obesity worsen insulin resistance, weight loss slows the progression of diabetes complications. Given the elevated risk for diabetes complications in patients with obesity, clinicians must understand how to treat obesity in their patients with diabetes, including providing counseling and behavioral management, referral to weight loss programs, and medication management. This article summarizes guidelines for diagnosing and managing obesity in people with diabetes.

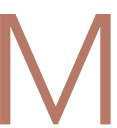
ore than $90 \%$ of patients with type 2 diabetes have a BMI $\geq 25.0 \mathrm{~kg} / \mathrm{m}^{2}$ (1). In 2013, the American Medical Association designated obesity as a chronic disease (2), and there is growing appreciation of obesity as a complex chronic condition caused by multiple factors, including behaviors, genetics, and the environment. Adipose tissue is an endocrine organ, releasing and responding to hormones that contribute to metabolic disease, including diabetes (2). Obesity affects all organ systems, causing increased rates of cardiovascular and renal disease, certain cancers, arthritis, and sleep apnea (3-6). Given the high prevalence of concomitant disease, most clinicians will have patients with both diabetes and obesity.

Previous studies have shown that a lack of time and training limits clinicians' desire to engage patients in weight management discussions $(7,8)$. However, research shows that clinicians can successfully provide behavioral counseling for obesity and also have important roles in referring to weight loss programs as needed, following up on patients' weight loss goals, and providing ongoing support and encouragement (9-13). Thus, it is important for clinicians to understand obesity treatment in patients with diabetes because modest weight losses of $3-5 \%$ of initial body weight improve glucose intolerance and A1C, slow complications of diabetes, reduce the need for glucose-lowering agents, and prevent the progression of prediabetes to type 2 diabetes $(3,14,15)$. This article will summarize guidelines for nonsurgical treatment of obesity in patients with diabetes.

\section{Diagnosing Obesity}

Obesity is traditionally diagnosed by BMI, which is an accurate approximation of adiposity for most individuals. Recent guidelines from the American Academy of Clinical Endocrinologists (AACE) and the American Heart Association/ American College of Cardiology/The Obesity Society (AHA/ACC/TOS) recommend that clinicians evaluate metabolic health in addition to BMI $(2,3)$. Patients should be screened for obesity with annual calculation of BMI after measuring both height and weight $(2,3)$. For patients with a BMI $\geq 25 \mathrm{~kg} / \mathrm{m}^{2}\left(\geq 23 \mathrm{~kg} / \mathrm{m}^{2}\right.$ in those 
TABLE 1. Weight-Related Complications Caused/Exacerbated by Excess Adiposity (2)

- Elevated blood pressure
- Hypertriglyceridemia
- Dypercholesterolemia
- Osteoarthritis
- Depression
- Sleep apnea

- Reactive airway disease

- Nonalcoholic fatty liver disease

- Gastroesophageal reflux disease

- Male hypogonadism

- Female infertility

- Polycystic ovary disease

- $\quad$ Stress urinary incontinence

whether clinicians will provide weight loss support in their practice or will be referring patients to a weight loss program.

\section{Weight Loss Goals}

Weight loss of $5-10 \%$ of baseline body weight is recommended as an initial goal of treatment, and this amount of weight loss is associated with a $0.6-1.0 \%$ reduction in $\mathrm{A} 1 \mathrm{C}$ and numerous other health improvements (3). However, weight loss of as little as $2-5 \%$ produces a clinically meaningful reduction in fasting blood glucose $(20 \mathrm{mg} / \mathrm{dL})$ (3). The American Diabetes Association (ADA) recommends that patients with prediabetes lose $7 \%$ of baseline body weight to avoid developing diabetes (23).

In adult patients with type 2 diabetes, cohort studies have shown that individuals who lost 9-13 kg had a $25 \%$ reduction in all-cause mortality compared to weight-neutral patients (3). In the Look AHEAD (Action for Health in Diabetes) trial, adults with type 2 diabetes and overweight/ obesity who were randomized to an intensive lifestyle intervention for weight loss had a $6.0 \%$ weight loss at 9 years compared to a $3.5 \%$ weight loss in the control group. Although the intervention group did not achieve a significant reduction in cardiovascular events compared to the control group, numerous other health improvements occurred, including reduced sleep apnea, lower $\mathrm{A} 1 \mathrm{C}$, reduced need for diabetes medications, improved mobility and quality of life, fewer hospitalizations, and reduced health care costs $(24,25)$. Moreover, a secondary analysis of participants who lost and sustained $\geq 10 \%$ of their body weight, which included $>25 \%$ of intervention subjects, did show significant improvements in cardiovascular morbidity and mortality (26-29). A sustained $7 \%$ weight loss improves many other outcomes in patients with diabetes and overweight/ obesity, including fitness, waist cir- 
TABLE 3. Common Commercial Weight Loss Programs' Weight Loss and Glycemic Outcomes In RCTs

\begin{tabular}{|c|c|c|c|c|c|}
\hline & Time Point & $\begin{array}{l}\text { Mean Weight } \\
\text { Loss at Time } \\
\text { Point (kg) }\end{array}$ & $\begin{array}{c}\text { RCTs Conducted } \\
\text { in Patients With } \\
\text { Diabetes? }\end{array}$ & $\begin{array}{l}\text { A1C Change at } \\
\text { Time Point (\%) }\end{array}$ & $\begin{array}{l}\text { Patients Who } \\
\text { Reduced } \\
\text { Diabetes } \\
\text { Medications at } \\
\text { Time Point (\%) }\end{array}$ \\
\hline Weight Watchers & 12 Months & -3.0 to -9.1 & No & - & - \\
\hline Jenny Craig & 12 Months & -6.6 to -10.1 & Yes & -0.3 to -0.7 & $\begin{array}{l}\text { 30-39 (oral); } \\
63-90 \text { (insulin) }\end{array}$ \\
\hline Nutrisystem & 6 Months & -7.3 to -10.8 & Yes & -0.7 & $\begin{array}{c}28 \text { (all } \\
\text { medications) }\end{array}$ \\
\hline
\end{tabular}

cumference, blood pressure, sexual functioning, and reported peripheral neuropathy symptoms $(15,26,27,30)$.

Clinician-Managed Weight Loss Support Versus Referral to a Weight Loss Program

When patients are ready to discuss weight loss strategies, clinicians should determine whether they are able to provide intensive counseling and follow-up for weight loss in their clinical practice or whether they should instead refer patients to an outside weight loss program. The 2016 ADA guidelines and the 2013 AHA/ ACC/TOS guidelines recommend that clinicians refer patients with obesity and type 2 diabetes to high-intensity programs $(3,23,31)$. Per these guidelines, high-intensity programs involve at least $14-16$ visits over 6 months. In-person programs result in more weight loss than electronically delivered interventions, but both produce more weight loss than no program (3). Whether clinicians provide intensive support for weight loss or refer patients to a high-intensity program, they should see patients at least every 3 months to monitor their blood glucose control because patients may require decreased doses of glucose-lowering medications as they lose weight (23).

Clinicians can consider managing weight loss in their patients if they are able to provide the high frequency of visits, as well as the necessary behavioral and nutritional support. Individualized weight loss support is also contingent on clinicians having enough time to take in-depth histories of patients' daily routines and eating behaviors (22). The AACE/ACE guidelines recommend that a weight loss intervention involve behavioral therapy focusing on goal-setting, education, selfmonitoring, problem-solving strategies, stimulus control, behavioral contracting, stress reduction, psychological evaluation (with treatment if indicated), cognitive restructuring, motivational interviewing, and mobilization of social support structures $(2,32)$. Medicare covers obesity screening and intensive counseling in the primary care setting, which may encourage clinicians to provide these services $(33,34)$.

Given the intensity of follow-up required, many clinicians may prefer to refer patients to evidence-based weight loss programs in their community. However, these clinicians need to be aware that guideline-adherent community weight loss programs may be difficult to find (35). Popular commercial weight loss programs are available in many communities, and guidelines suggest that referral to an evidence-based commercial weight loss program that has documented efficacy via rigorous scientific studies is an acceptable strategy (3).

Table 3 summarizes outcomes with Weight Watchers, Jenny Craig, and Nutrisystem, which typically comprise the majority market share in the commercial weight loss industry (31,36-41). Both Weight Watchers and Jenny Craig have had randomized, controlled trials (RCTs) documenting their long-term weight loss efficacy, and Jenny Craig has demonstrated long-term glycemic benefits among patients with diabetes $(3,42-44)$.

Another community referral option is the Centers for Disease Control and Prevention (CDC) National Diabetes Prevention Program (DPP), which is based on the Diabetes Prevention Program RCT, in which an intensive behavioral program delayed the development of type 2 diabetes and showed a $58 \%$ reduced progression to diabetes compared to a control group $(45,46)$. Patients with prediabetes can be referred to a clinical center or YMCA that has a certified National DPP program. Beginning in January 2018, National DPP interventions will be covered by Medicare, which is a significant benefit for Medicare patients with prediabetes (47).

\section{Behavioral Components of Weight Loss and Weight Loss Maintenance}

The goal of weight-related behavioral changes and programs should be to achieve a caloric deficit of 500-750 $\mathrm{kcal} /$ day $(3,23)$. Dietary approaches that selectively restrict fat or carbohydrates or selectively increase protein or fiber are equally effective in producing weight loss if they meet the targeted reduction in calories (Table 4) $(3,23)$. Each of these dietary approaches is considered safe for patients with diabetes, and each is effective if patients are able to adhere to the caloric restrictions $(2,23)$. Patients may believe that they will have a higher likelihood of 
TABLE 4. Eating Patterns With Equivalent Effects on Weight

Loss (2)

$$
\begin{aligned}
& \text { - Low glycemic index/load } \\
& \text { - High protein } \\
& \text { - Low fat }
\end{aligned}
$$

success if they use a meal-replacement option, and this option may be particularly helpful to patients who have limited time or ability to prepare food. As patients achieve caloric reduction, they may need to monitor their blood glucose more often depending on which glucose-lowering medications(s) they take.

It is important to understand that reducing caloric intake is more effective at achieving initial weight loss than only increasing exercise $(48,49)$. Patients who made dietary changes alone lost $7 \mathrm{~kg}$ more at the 6-month follow-up than patients who added physical activity alone (49). Physical activity remains important for maintaining weight loss but should not be the primary focus of behavioral change for weight loss. Patients on insulin should increase glucose monitoring when starting a new exercise regimen to avoid hypoglycemia during or after exercise. The CDC does recommend that all adults, regardless of their weight or diabetes status, get $150 \mathrm{~min} /$ week of moderate aerobic activity and perform resistance exercise twice per week (32). Achieving this amount of physical activity, as well as avoiding long periods of inactivity, are good initial goals for patients who are not physically active (2).

Self-monitoring is another important tool in weight loss and weight maintenance efforts (50). Daily self-weighing has been shown to improve individuals' ability to refrain from excess caloric intake (51) and thus promotes weight loss (52). Breaks in daily weighing are associated with weight regain (52). Additionally, both the AHA/ACC/ TOS and AACE/ACE guidelines rec-

\section{- Low carbohydrate \\ - Moderate carbohydrate- moderate protein}

- Mediterranean style

ommend monitoring physical activity and food intake $(3,53)$.

For maintaining weight loss, the ADA guidelines recommend that patients with diabetes be referred to a long-term (at least 1 year) weight maintenance program that involves at least monthly visits, at least weekly weight measurements, and at least 200-300 $\mathrm{min} /$ week of physical activity (23).

\section{Medication Management}

In addition to promoting patients' healthy lifestyle changes, managing medications is an important role for clinicians in treating patients with type 2 diabetes and obesity. Clinicians should consider altering the diabetes medication regimen and using weight loss medications for these patients.

First, clinicians should consider using the following glucose-lowering medications that are weight neutral or may promote weight loss: metformin, pramlintide, glucagon-like peptide 1 (GLP-1) receptor agonists, dipeptidyl peptidase 4 (DPP-4) inhibitors, and sodium-glucose cotransporter 2 (SGLT2) inhibitors. Metformin has been associated with a 3 -kg weight loss $(23,54-56)$. In addition to being associated with a $3.7-\mathrm{kg}$ weight loss, pramlintide can also lower daily insulin requirements in patients with diabetes on insulin therapy (57). GLP-1 receptor agonists have been associated with a $5.3-\mathrm{kg}$ weight loss (58). DPP-4 inhibitors are generally weight neutral $(59,60)$. Finally, SGLT2 inhibitors can promote a $2.4-\mathrm{kg}$ weight loss and lower insulin requirements (61). Of note, there is generally no benefit to using DPP-4 inhibitors and GLP-1 receptor agonists simultaneously because they work on the same pathway. Further discussion on pharmacotherapy for obesity in patients with diabetes is covered elsewhere in this issue (p. 250).

In addition to avoiding diabetes medications that are associated with weight gain (e.g., sulfonylureas, thiazolidinediones, and insulin), clinicians should also assess for other medications that are associated with weight gain. When possible, clinicians should attempt to reduce or find alternatives to common medications that can increase appetite and promote weight gain, including sedating antihistamines, steroids, some selective serotonin reuptake inhibitors, beta-blockers, and most antipsychotic agents (62).

The AACE/ACE guidelines recommend that patients with diabetes and a BMI $\geq 27 \mathrm{~kg} / \mathrm{m}^{2}$ be prescribed weight loss medications (53). Treatment of obesity through pharmacotherapy, in conjunction with a healthy lifestyle, directly improves glycemic control $(63,64)$. Five medications are now approved by the U.S. Food and Drug Administration (FDA) for long-term use for weight loss. Table 5 provides an overview of their weight loss and $\mathrm{A} 1 \mathrm{C}$ outcomes and their side effects (62,65-69). Additionally, sympathomimetic appetite suppressant medications are approved for shortterm use (up to 12 weeks). To avoid weight regain, the ADA recommends long-term use of weight loss medication for patients who successfully lose weight on the medication. Therefore, this article will focus only on medications approved for long-term use (70). For patients whose weight loss is $<5 \%$ of initial body weight after the initial treatment period on a given medication (various medications have different initial treatment periods), the medication should be discontinued and an alternative medication or approach should be tried (23). The AACE/ACE guidelines recommend monitoring patients who are on insulin or sulfonylureas for hypoglycemia after starting any weight loss medication $(2,53)$. When considering these 


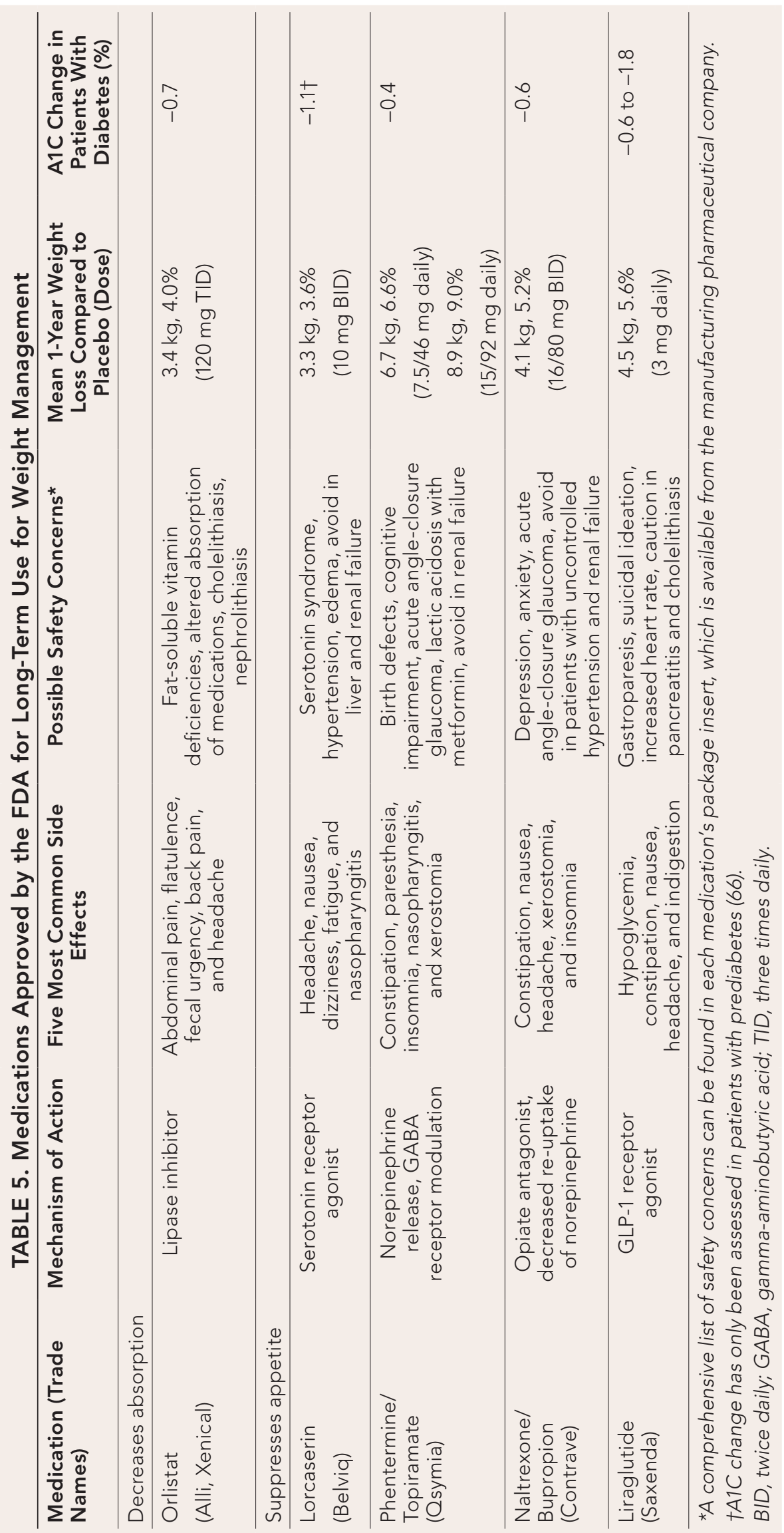

medications, clinicians should discuss typical weight loss results, side effects, and medication costs with their patients.

\section{Obesity Treatment in Type 1 Diabetes}

Obesity is increasingly common in patients with type 1 diabetes; in $1988,25 \%$ of 40 - to 49 -year-olds with type 1 diabetes had overweight or obesity compared to $68 \%$ in 2007 (71). Patients with type 1 diabetes will need to continue to take their insulin and strive for a caloric reduction of 500-700 kcal/day to lose weight. The ADA recommends that adults with type 1 diabetes meet the CDC recommendations for physical activity for all adults $-150 \mathrm{~min} /$ week of moderate aerobic activity and two sessions of resistance training per week (23). Patients with type 1 diabetes starting a new exercise regimen or caloric reduction will need to monitor closely for hypoglycemia. In addition, the weight loss medications described above can also be considered for patients with type 1 diabetes. Pramlintide may be considered in patients with type 1 diabetes as a means of reducing their insulin requirements and promoting weight loss.

\section{Conclusion}

Weight loss is particularly important for individuals who have both diabetes and obesity. Because of the high prevalence of their co-occurrence, clinicians should be aware of the guidelines for treating obesity in patients with type 2 diabetes. The ADA, $\mathrm{AACE} / \mathrm{ACE}$, and AHA/ACA/TOS guidelines all recommend referring patients to high-intensity weight loss programs. Caloric reduction is the mainstay of weight loss, and increased exercise is crucial for maintaining weight loss. Medication management is also important for these patients, whether that involves selecting diabetes medications that promote weight loss or are weight neutral, prescribing medications approved for weight loss, or both. 


\section{Funding}

C.T.B. is funded by the National Heart, Lung, and Blood Institute (T32HL00718041A1). C.J.L. is funded by a career development award from the National Institute of Diabetes and Digestive and Kidney Disease (K23DK107921). K.A.G. is funded by a career development award from the National Heart, Lung, and Blood Institute (K23HL116601)

\section{Duality of Interest}

No potential conflicts of interest relevant to this article were reported.

\section{References}

1. World Health Organization. Obesity and overweight fact sheet [Internet]. Available from http://www.who.int/dietphysical activity/media/en/gsfs_obesity.pdf. Accessed April 2017

2. Garvey WT, Mechanick JI, Brett EM, et al. American Association of Clinical Endocrinologists and American College of Endocrinology comprehensive guidelines for medical care of patients with obesity. Endocr Pract 2016;22(Suppl. 3):1-203

3. Jensen MD, Ryan DH, Apovian CM, et al. 2013 AHA/ACC/TOS guideline for the management of overweight and obesity in adults: a report of the American College of Cardiology/American Heart Association Task Force on Practice Guidelines and The Obesity Society. J Am Coll Cardiol 2014; 63:2985-3023

4. Macumber I, Schwartz S, Leca N. Maternal obesity is associated with congenital anomalies of the kidney and urinary tract in offspring. Pediatr Nephrol 2017;32:635-642

5. Mitchell A, Fantasia HC. Understanding the effect of obesity on fertility among reproductive-age women. Nurs Womens Health 2016;20:368-376

6. Simeone RM, Tinker SC, Gilboa SM, et al. Proportion of selected congenital heart defects attributable to recognized risk factors. Ann Epidemiol 2016;26:838-845

7. Bleich SN, Bennett WL, Gudzune KA, Cooper LA. National survey of US primary care physicians' perspectives about causes of obesity and solutions to improve care. BMJ Open 2012;2:e01871

8. Kushner RF. Barriers to providing nutrition counseling by physicians: a survey of primary care practitioners. Prev Med 1995;24:546-552

9. Bennett WL, Gudzune KA, Appel LJ, Clark JM. Insights from the POWER practice-based weight loss trial: a focus group study on the PCP's role in weight management. J Gen Intern Med 2014;29:50-58

10. Bennett WL, Wang NY, Gudzune KA, et al. Satisfaction with primary care provider involvement is associated with greater weight loss: results from the practice-based
POWER trial. Patient Educ Couns 2015;98:1099-1105

11. Gudzune KA, Bennett WL, Cooper LA, Bleich SN. Perceived judgment about weight can negatively influence weight loss: a cross-sectional study of overweight and obese patients. Prev Med 2014;62:103-107

12. Moyer VA; U.S. Preventive Services Task Force. Screening for and management of obesity in adults: U.S. Preventive Services Task Force recommendation statement. Ann Intern Med 2012;157:373-378

13. Leblanc ES, O'Connor E, Whitlock EP, Patnode CD, Kapka T. Effectiveness of primary care-relevant treatments for obesity in adults: a systematic evidence review for the U.S. Preventive Services Task Force. Ann Intern Med 2011;155:434-447

14. Appel LJ, Champagne CM, Harsha DW, et al. Effects of comprehensive lifestyle modification on blood pressure control: main results of the PREMIER clinical trial. JAMA 2003;289:2083-2093

15. Look AHEAD Research Group. Effects of a long-term lifestyle modification programme on peripheral neuropathy in overweight or obese adults with type 2 diabetes: the Look AHEAD study. Diabetologia 2017;60:980-988

16. Huizinga MM, Cooper LA, Bleich SN, Clark JM, Beach MC. Physician respect for patients with obesity. J Gen Intern Med 2009;24:1236-1239

17. Puhl RM, Moss-Racusin CA, Schwartz MB. Internalization of weight bias: implications for binge eating and emotional well-being. Obesity (Silver Spring) 2007:15:19-23

18. Alexander SC, Cox ME, Boling Turer $\mathrm{CL}$, et al. Do the five A's work when physicians counsel about weight loss? Fam Med 2011;43:179-184

19. Jay M, Gillespie C, Schlair S, Sherman $\mathrm{S}$, Kalet A. Physicians' use of the 5As in counseling obese patients: is the quality of counseling associated with patients' motivation and intention to lose weight? BMC Health Serv Res 2010;10:159

20. Serdula MK, Khan LK, Dietz WH. Weight loss counseling revisited. JAMA 2003;289:1747-1750

21. Whitlock EP, Orleans CT, Pender N, Allan J. Evaluating primary care behavioral counseling interventions: an evidence-based approach. Am J Prev Med 2002;22:267-284

22. Gudzune K. Dietary and behavioral approaches in the management of obesity. Gastroenterol Clin North Am 2016;45:653-661

23. American Diabetes Association. Standards of medical care in diabetes-2016: abridged for primary care providers. Clin Diabetes 2016;34:3-21

24. Pi-Sunyer $X$. The Look AHEAD trial: a review and discussion of its outcomes. Curr Nutr Rep 2014;3:387-391
25. Espeland MA, Glick HA, Bertoni A, et al.; Look AHEAD Research Group. Impact of an intensive lifestyle intervention on use and cost of medical services among overweight and obese adults with type 2 diabetes: the Action for Health in Diabetes. Diabetes Care 2014;37:2548-2556

26. Look AHEAD Research Group; Wing RR, Bolin P, Brancati FL, et al. Cardiovascular effects of intensive lifestyle intervention in type 2 diabetes. N Engl J Med 2013;369:145-154

27. Gibbs BB, Brancati FL, Chen H, et al., for the Look AHEAD Research Group. Effect of improved fitness beyond weight loss on cardiovascular risk factors in individuals with type 2 diabetes in the Look AHEAD study. Eur J Prev Cardiol 2014;21:608-617

28. Rapp SR, Luchsinger JA, Baker LD, et al; Look AHEAD Research Group. Effect of a long-term intensive lifestyle intervention on cognitive function: Action for Health in Diabetes study. J Am Geriatr Soc 2017;65:966-972

29. Look AHEAD Research Group; Gregg EW, Jakicic JM, Blackburn G, et al. Association of the magnitude of weight loss and changes in physical fitness with long-term cardiovascular disease outcomes in overweight or obese people with type 2 diabetes: a post-hoc analysis of the Look AHEAD randomised clinical trial. Lancet Diabetes Endocrinol 2016;4:913-921

30. Wing RR, Bond DS, Gendrano IN 3rd, et al.; Sexual Dysfunction Subgroup of the Look AHEAD Research Group. Effect of intensive lifestyle intervention on sexual dysfunction in women with type 2 diabetes: results from an ancillary Look AHEAD study. Diabetes Care 2013;36:2937-2944

31. Jolly K, Lewis A, Beach J, et al. Comparison of range of commercial or primary care led weight reduction programmes with minimal intervention control for weight loss in obesity: Lighten Up randomised controlled trial. BMJ 2011;343:d6500

32. Centers for Disease Control and Prevention. How much physical activity do adults need? [Internet]. Available from https://www.cdc.gov/physicalactivity/basics/ adults/index.htm. Accessed 27 April 2017

33. U.S Preventive Services Task Force. Obesity in adults: screening and management [Internet]. Available from http://www. uspreventiveservicestaskforce.org/uspstf/ uspsobes.htm. Accessed 30 April 2017

34. Sebelius K. Report to Congress on preventive services and obesity-related services available to Medicaid enrollees [Internet]. Availble from https://www.medicaid.gov/ medicaid/quality-of-care/downloads/ rtc-preventive-obesity-related-services 2014. pdf. Accessed 30 April 2017

35. Bloom B, Mehta AK, Clark JM, Gudzune KA. Guideline-concordant weight-loss programs in an urban area are uncommon and difficult to identify 
through the Internet. Obesity (Silver Spring) 2016;24:583-588

36. Foster GD, Wadden TA, Lagrotte $\mathrm{CA}$, et al. A randomized comparison of a commercially available portion-controlled weight-loss intervention with a diabetes self-management education program. Nutr Diabetes 2013;3:e63

37. Rock CL, Flatt SW, Pakiz B, et al. Weight loss, glycemic control, and cardiovascular disease risk factors in response to differential diet composition in a weight loss program in type 2 diabetes: a randomized controlled trial. Diabetes Care 2014:37:1573-1580

38. Pinto AM, Fava JL, Hoffmann DA, Wing RR. Combining behavioral weight loss treatment and a commercial program: a randomized clinical trial. Obesity (Silver Spring) 2013;21:673-680

39. Foster GD, Borradaile KE, Vander Veur $\mathrm{SS}$, et al. The effects of a commercially available weight loss program among obese patients with type 2 diabetes: a randomized study. Postgrad Med 2009;121:113-118

40. Rock CL, Pakiz B, Flatt SW, Quintana EL. Randomized trial of a multifaceted commercial weight loss program. Obesity (Silver Spring) 2007;15:939-949

41. Jolly K, Daley A, Adab P, et al. A randomised controlled trial to compare a range of commercial or primary care led weight reduction programmes with a minimal intervention control for weight loss in obesity: the Lighten Up trial. BMC Public Health 2010;10:439

42. Gudzune KA, Doshi RS, Mehta AK, et al. Efficacy of commercial weight-loss programs: an updated systematic review. Ann Intern Med 2015;162:501-512

43. Johnston BC, Kanters S, Bandayrel K, et al. Comparison of weight loss among named diet programs in overweight and obese adults: a meta-analysis. JAMA 2014;312:923-933

44. Chaudhry ZW, Doshi RS, Mehta AK, et al. A systematic review of commercial weight loss programmes' effect on glycemic outcomes among overweight and obese adults with and without type 2 diabetes mellitus. Obes Rev 2016;17:758-769

45. Knowler WC, Barrett-Connor E, Fowler $\mathrm{SE}$, et al. Reduction in the incidence of type 2 diabetes with lifestyle intervention or metformin. N Engl J Med 2002;346:393-403

46. Knowler WC, Fowler SE, Hamman RF, et al. 10-year follow-up of diabetes incidence and weight loss in the Diabetes Prevention Program Outcomes Study. Lancet 2009;374:1677-1686

47. U.S. Department of Health and Human Services. Certification of Medicare Diabetes Prevention Program [Internet]. Available from https://www.cms.gov/ResearchStatistics-Data-and-Systems/Research/ ActuarialStudies/Downloads/Diabetes-
Prevention-Certification-2016-03-14.pdf. Accessed 8 April 2017

48. Dansinger ML, Gleason JA, Griffith JL, Selker HP, Schaefer EJ. Comparison of the Atkins, Ornish, Weight Watchers, and Zone diets for weight loss and heart disease risk reduction: a randomized trial. JAMA 2005;293:43-53

49. Wing RR, Venditti E, Jakicic JM, Polley BA, Lang W. Lifestyle intervention in overweight individuals with a family history of diabetes. Diabetes Care 1998;21:350-359

50. Voils CI, Olsen MK, Gierisch JM, et al. Maintenance of weight loss after initiation of nutrition training: a randomized trial. Ann Intern Med 2017;166:463-471

51. Butryn ML, Phelan S, Hill JO, Wing RR. Consistent self-monitoring of weight: a key component of successful weight loss maintenance. Obesity (Silver Spring) 2007:15:3091-3096

52. Helander EE, Vuorinen AL, Wansink B, Korhonen IK. Are breaks in daily self-weighing associated with weight gain? PLoS One 2014;9:e113164

53. Garber AJ, Abrahamson MJ,

Barzilay JI, et al. Consensus statement by the American Association of Clinical Endocrinologists and American College of Endocrinology on the comprehensive type 2 diabetes management algorithm-2017: executive summary. Endocr Pract 2017;23:207-238

54. Diabetes Prevention Program Research Group. Long-term safety, tolerability, and weight loss associated with metformin in the Diabetes Prevention Program Outcomes Study. Diabetes Care 2012;35:731-737

55. Fontbonne A, Diouf I, Baccara-Dinet M, Eschwege E, Charles MA. Effects of 1-year treatment with metformin on metabolic and cardiovascular risk factors in non-diabetic upper-body obese subjects with mild glucose anomalies: a post-hoc analysis of the BIGPRO1 trial. Diabetes Metab 2009;35:385-391

56. Seifarth C, Schehler B, Schneider HJ. Effectiveness of metformin on weight loss in non-diabetic individuals with obesity. Exp Clin Endocrinol Diabetes 2013;121:27-31

57. Aronne L, Fujioka K, Aroda V, et al. Progressive reduction in body weight after treatment with the amylin analog pramlintide in obese subjects: a phase 2 , randomized, placebo-controlled, dose-escalation study. J Clin Endocrinol Metab 2007;92:2977-2983

58. Klonoff DC, Buse JB, Nielsen LL, et al. Exenatide effects on diabetes, obesity, cardiovascular risk factors and hepatic biomarkers in patients with type 2 diabetes treated for at least 3 years. Curr Med Res Opin 2008;24:275-286

59. Pratley RE, Kipnes MS, Fleck PR, Wilson C, Mekki Q, Alogliptin Study Group. Efficacy and safety of the dipeptidyl peptidase-4 inhibitor alogliptin in patients with type 2 diabetes inadequately controlled by glyburide monotherapy. Diabetes Obes Metab 2009;11:167-176

60. Raz I, Chen Y, Wu M, et al. Efficacy and safety of sitagliptin added to ongoing metformin therapy in patients with type 2 diabetes. Curr Med Res Opin 2008;24:537-550

61. Rosenstock J, Jelaska A, Frappin G, et al. Improved glucose control with weight loss, lower insulin doses, and no increased hypoglycemia with empagliflozin added to titrated multiple daily injections of insulin in obese inadequately controlled type 2 diabetes. Diabetes Care 2014;37:1815-1823

62. Apovian CM, Aronne LJ, Bessesen $\mathrm{DH}$, et al. Pharmacological management of obesity: an Endocrine Society clinical practice guideline. J Clin Endocrinol Metab 2015;100:342-362

63. Goldstein DJ. Beneficial health effects of modest weight loss. Int J Obes Relat Metab Disord 1992;16:397-415

64. U.K. Prospective Diabetes Study Group: UKPDS 7: response of fasting plasma glucose to diet therapy in newly presenting type II diabetic patients. Metabolism 1990;39:905-912

65. Jacob S, Rabbia M, Meier MK, Hauptman J. Orlistat $120 \mathrm{mg}$ improves glycaemic control in type 2 diabetic patients with or without concurrent weight loss. Diabetes Obes Metab 2009;11:361-371

66. Mahgerefteh B, Vigue M, Freestone Z, Silver S, Nguyen Q. New drug therapies for the treatment of overweight and obese patients. Am Health Drug Benefits 2013;6:423-430

67. Garvey WT, Ryan DH, Look M, et al. Two-year sustained weight loss and metabolic benefits with controlled-release phentermine/topiramate in obese and overweight adults (SEQUEL): a randomized, placebo-controlled, phase 3 extension study. Am J Clin Nutr 2012;95:297-308

68. Makowski CT, Gwinn KM, Hurren KM Naltrexone/bupropion: an investigational combination for weight loss and maintenance. Obes Facts 2011;4:489-494

69. Bays H, Pi-Sunyer X, Hemmingsson JU, Claudius B, Jensen CB, Van Gaal L. Liraglutide $3.0 \mathrm{mg}$ for weight management: weight-loss dependent and independent effects. Curr Med Res Opin 2017;33:225-229

70. Heymsfield SB, Wadden TA.

Mechanisms, pathophysiology, and management of obesity. N Engl J Med 2017;376:254-266

71. Conway B, Miller RG, Costacou T, et al. Temporal patterns in overweight and obesity in type 1 diabetes. Diabet Med 2010;27:398-404 